\title{
Comparative Study of Construction/Flat Patterns and Grading Patterns Application in Clothing Making: A Case Study on Women's Clothing Practices
}

\author{
Marniati \\ Department of Home Economics, Faculty of Engineering, Universitas Negeri Surabaya, Surabaya, Indonesia \\ marniati@unesa.ac.id \\ Corresponding Author : marniati@unesa.ac.id | Phone : +628121658356
}

\begin{abstract}
This study aimed to measure the implementation of the practice in the women's clothing course in terms of the skill variable making construction/flat clothing patterns, applying the grading pattern and making women's clothing. This study used a quantitative approach. The research subjects were all students who programmed the women's clothing course. 43 students of the UNESA Fashion Design Education undergraduate study program. Data analysis used $2 \times 4$ factorial ANOVA followed by a comparison of the mean using SPSS software. The honest real difference test (Tukey test) was used to test the difference between the two data at the $5 \%$ significance level. Observations were made on two things, namely the length of time for making patterns and clothes, on industrial and custom-made clothing. Industrial clothing consists of one-pieces, blouses/tunics, skirts, and pants, while costume-made clothing consists of deuce pieces, long dresses, short dresses, and modern kebaya. The method of making patterns reads into two ways, namely flat and grading. The results showed that the grading method can speed up the time for making industrial and custom-made clothing patterns. The manufacture of one-piece industry clothing takes longer than others. Meanwhile, the long costume-made dress takes longer than the others.
\end{abstract}

Keywords: Industrial clothing; Costume-made; Construction/flat pattern;

\section{Introduction}

The fashion industry in Indonesia has developed rapidly, both in the production and service sectors. Some of the specialists (companies) in the fashion industry include haute couture, ateliers, boutiques, modiste, and garment. According to Marwiyah (2010), the garment/convection industry is an industry that makes clothing in bulk without measuring consumers but using standard sizes. Clothing is then classified into various sizes, whether small, medium, and large, or differentiated by numbers such as No.1, 2, 3, or others. Dai \& Wang (2011) stated that the efficiency and accuracy in input production and garment pattern grading can be improved. The system has been well received in practical applications.

McLendon, D. L. (2011) stating pattern grading is a method of making several sizes of clothing styles. Judging to extreme sizes is not recommended as garment designs and curtains can be distorted. Furthermore, McLendon stated that a series of activities in using pattern grading must be carried out such as; the fittings and drapes of the

original base size garment have the greatest influence on the fit and drape of the derived sizes.

So far, the practice in the women's clothing course-1/Industry and practitioners in the women's clothing course-2 uses a construction pattern/flat on papers. Making flat patterns for the practice of making clothes takes a long time, considering that students have to follow predetermined procedures. According to Wening (2013), several steps are needed in arranging a pattern flat on paper: (1) analyzing the design, (2) measuring the body, (3) making a master pattern or determining how to make a master pattern, (4) modifying the pattern master (based on design analysis feedback) to make a ready-made pattern that fits in to the fashion design (pattern split), and (5) outlines the parts of the pattern.

The steps above are in line with Armstrong, (2010) who says that:

The process of making flat patterns in fashion design is as follows: First, analyzing the design and identifying the creative elements; Second, the pattern maker identifies which technique will be used to create the pattern on the design, especially three-dimensional replica designs. Other design elements that do not change the shape of the pattern are still part of the finished design; Third, the work pattern in the form of a 
split pattern or tracing copy is obtained using the slash or pivotal method against the original pattern.

This condition was repeated when students practiced clothing with a high level of difficulty so that they did the fittings repeatedly to get maximum results. This has implications for the length of completion time in the production of these clothes, and of course, affects the lecture schedule which is limited by the weight of the credits in the course. Therefore, the problem must be identified to prepare an immediate solution.

Meanwhile, several other courses discuss the problem of pattern making, which so far has not been reintegrated directly into the women's clothing course, namely grading technique and draping technique. Pattern grading is about maximizing or minimizing standard patterns to produce new patterns at a certain size. Herman et al. (2011) states that pattern grading is a process to maximize or reduce the size of a fashion or shoe pattern into various standard sizes in the garment industry. Meanwhile Dove (2016) investigated construction patterns that were block-like grading patterns with identification for woven and jersey garments, and expectations of a suitable garment fit, comparing the two published pattern-making methods.

Cooklin (2003) stated that pattern grading is a technique used to increase or decrease the size of a clothing pattern according to the measurements in a certain size table. This must be done accurately because small errors that go unnoticed when one measure is judged becomes difficult when multiple measures are required. An accurate method is capable of compiling the smallest and largest sizes. Sizes usually stop between lines drawn through the base points. The practice of pattern grading in the garment industry usually uses medium size $(\mathrm{M})$ because it facilitates maximizing the pattern to large (L) sizes or minimizing it to small sizes (S). The targets of this grading pattern include: (1) operational management to ensure that production is carried out efficiently and effectively; and (2) using pattern techniques to get the right pattern with a fast process. A similar opinion is also expressed by Price \& Zamkoff (1996) which states that the grading pattern is an effort to proportionally increase or decrease a parent pattern according to a set of determined body sizes. The benefits of pattern assessment are (1) more precise pattern analysis; (2) fashion fittings are better in size or wearability; and (3) the processing time is more efficient than the flat pattern.

Meanwhile, the draping technique is to create a technique for making patterns and clothes directly on the dress form/mannequin/doll/body sculpture using clothes media. Following Volpintesta (2014) statement that draping is an art and craft of taking fabric onto the body or dress form/mannequin with scissors, pins, and pencil to cut, secure, slash, and mark the fabric to create pattern/clothes. Draping is also commonly referred to as making patterns in three dimensions. There are 4 advantages of pattern making with draping techniques; (1) knowing the proportion of design lines on the body, (2) knowing whether the pattern is fitting on the body, (3) knowing the balance of the design lines on the body, (4) knowing/being able to see the style of the clothes.

The step taken is to combine grading and draping techniques to produce a pattern that can be practiced for all types of clothing. Namely by doing grading on the dress form. To find out the combination of the two techniques, observation/research was carried out on the application of making construction/flat clothing patterns, the application of grading patterns in the making of women's clothing, which aims to measure the Implementation of Practices in the Women's Clothing Course- 1 and 2.

\section{Materials and Methods}

\subsection{Clothing Making}

This research took place from September - December 2019 practice in the women's clothing course-1 (Industrial clothing) and January - April 2020 Practice in the Women's Clothing Course-2 (Costume-made Clothing) which was attended by 43 students who were asked to carry out the pattern-making process and make/sew clothes according to a predetermined design. At each stage, the time required in minutes will be measured. Industrial clothing products: one-pieces, blouses/tunics, skirts, and pants, while costume-made clothing consists of deuce pieces, long dresses, short dresses, and modern kebaya. In these two clothes, the pattern-making stage is done using two pattern-making methods, namely making the pattern in construction/flat and grading on the dress form.

\subsection{Statistical Data Analysis}

Data analysis used 2x4 factorial ANOVA followed by a comparison of the mean using SPSS software. The first factor is the pattern making method consisting of 2 levels, and the second factor is the type of clothing which consists of 4 levels. The honest real difference test (Tukey test) was used to test the difference between the two data at the $5 \%$ significance level. 


\section{Results And Discussions}

ANOVA results at the stage of making fashion patterns both in construction/flat, as well as in grading and in the stage of making clothes for practice in industrial clothing and custom-made clothing are as follows:

Table 1. Length of Time for Making Clothing Patterns (minutes)

\begin{tabular}{lcr}
\hline & \multicolumn{2}{c}{ Patterns } \\
\cline { 2 - 3 } & Flat & Grading \\
\hline Industrial Clothing & & $160.93^{\mathrm{d}}$ \\
One-Piece & $208.37^{\mathrm{d}}$ & $174.19^{\mathrm{c}}$ \\
Blouse/Tunic & $189.53^{\mathrm{c}}$ & $86.05^{\mathrm{a}}$ \\
Skirt & $110.23^{\mathrm{a}}$ & $131.16^{\mathrm{b}}$ \\
Pants & $161.16^{\mathrm{b}}$ & $148.84^{\mathrm{b}}$ \\
\hline Costume-Made Clothing & & $221.40^{\mathrm{d}}$ \\
Deuce Piece & $251.74^{\mathrm{c}}$ & $194.19^{\mathrm{c}}$ \\
Long dress & $270.00^{\mathrm{d}}$ & $113.72^{\mathrm{a}}$ \\
Short dress & $245.12^{\mathrm{b}}$ & $136.98^{\mathrm{a}}$ \\
Modern kebaya & $11{ }^{\mathrm{a}}$ & \\
\hline
\end{tabular}

Notes: average in one pattern with the same letter notation means there is no significant difference in $\alpha=0.05$

The data above proves the ANOVA results for the time of making industrial clothing patterns are significantly influenced by the pattern factor $(F=632,918 ; \mathrm{p}<0.05)$ and the clothing type factor $(\mathrm{F}=1206,497$; $\mathrm{p}<0.05$ ). The average time for making industrial clothing patterns using a flat pattern is 167.33 minutes, and 138.08 minutes when using a grading pattern.

Likewise, the making of custom-made clothing patterns was significantly influenced by the pattern factor $(F=2845.120 ; p<0.05)$ and the clothing type factor $(F=2391.111 ; p<0.05)$. The average time for making a costume-made fashion pattern using a flat pattern is 225.96 minutes, and 169.53 minutes when using a grading pattern.

This shows that using patterns with grading techniques can speed up the time for making industrial and custom-made clothing patterns. This is following Price \& Zamkoff (1996) opinion which states that the grading pattern is an effort to proportionally increase or decrease a parent pattern according to a set of determined body sizes, and other benefits are (1) more precise pattern analysis; (2) fashion fittings are better in size or wearability; and (3) the processing time is more efficient than the flat pattern

Table 2. Time Length for Clothing Making (minutes)

\begin{tabular}{lc}
\hline & Time \\
\hline Industrial Clothes & $289.77^{\mathrm{b}}$ \\
One-Piece & $254.77^{\mathrm{a}}$ \\
Blouse/Tunic & $254.77^{\mathrm{a}}$ \\
Skirt & $254.07^{\mathrm{a}}$ \\
Pants & $867.67^{\mathrm{a}}$ \\
\hline Costume-Made Clothes & $1203.49^{\mathrm{d}}$ \\
Deuce Piece & $891.28^{\mathrm{b}}$ \\
Long dress & $1116.05^{\mathrm{c}}$ \\
Short dress & \\
Modern kebaya & \\
\hline
\end{tabular}

Notes: average in one pattern with the same letter notation means there is no significant difference at $\alpha=0.05$

The one-piece industry clothing manufacture takes longer than others. While the long dress costumemade takes longer than others. In the final stage, namely, the sewing process to complete the clothes, the industrial clothing takes an average of 263.34 minutes and 1019.62 minutes for costume-made clothes. 


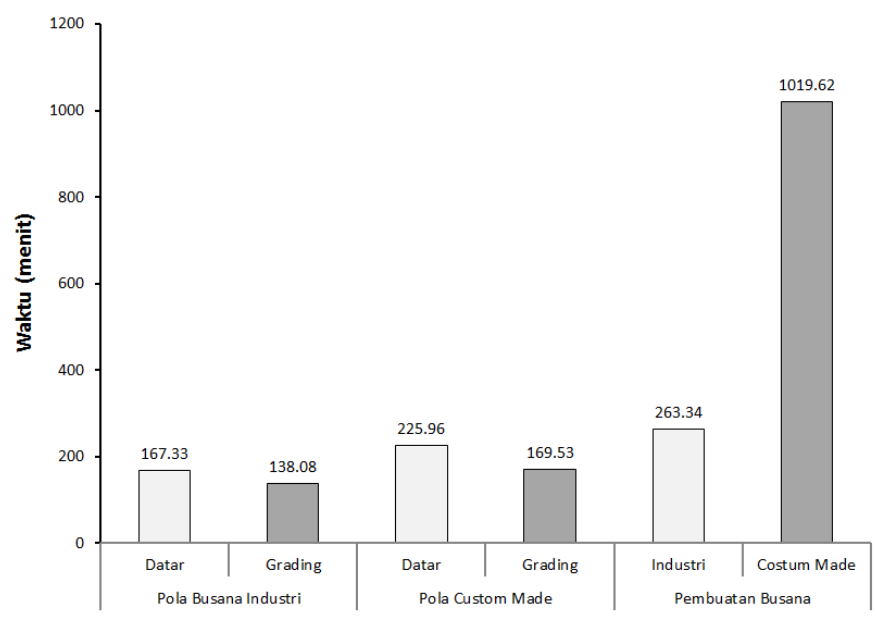

Figure 1. Time for Patterns and Clothing Making

The time length for making industrial clothing patterns using grading patterns is faster than flat patterns. Skirt type clothing patterns have the fastest time of 86.05 minutes when using a grading pattern. Whereas in the making of custom made clothing patterns, the shortest time is in modern kebaya clothes with 113.72 minutes.

After the fashion pattern creation is complete, you will continue to the sewing stage to complete the final part. At this stage, there is no longer the application of flat patterns or grading. The one-piece clothing industry takes 289.77 minutes, and this is much longer than the fashion of blouses/tunics, skirts and, pants. Whereas in costume-made clothes the longest time is in the long dress.

Observation of the pattern assessment starts from the tool design to the use of the pattern master with the pattern assessment tools/media flat following the expected design. The possible benefits of pattern assessment include: (1) more precise pattern analysis; (2) fashion fittings are better in size or wearability; and (3) the processing time is more efficient than the flat pattern. As stated by Mulyawan (2011) one of the goals of pattern grading is to get the expected pattern more quickly based on the size that is closer to one's desires.

The result of factorial ANOVA also proves that the making of patterns on industrial clothing is: (1) the length of time for pattern making is influenced by the method and product, (2) The effect of production factors is stronger than the manufacturing method. It can be proven that the grading method takes less time (faster) than the flat method, (3) There is no significant difference, the pattern making time for one-piece and blouse/unique products, (4) If sorted, the products that require longer periods in pattern making were: (a) one-pieces and blouses/tunics; (b) pants; and (c) skirts. As shown in table 1 and table 2.

This is consistent with the findings of Hlaing et al. (2013) in their research developed a 3D virtual model of the female body, namely; 3D virtual models and resulting trouser designs according to basic designs or block patterns can be offered to the garment industry. The job of the designer or stylist is only to determine the desired pattern design on the made shell of the pants. Hence, this approach is also very viable for the pattern maker which proves to be fast and economical.

Meanwhile, the factorial ANOVA results for the length of time for making costume-made patterns are: (1) The length of time for making costume-made clothing patterns is influenced by the method and product. The production factors influence is stronger than the manufacturing method, (2) The grading method takes less time (faster) than the flat method, (3) All products have a significant difference in the time of costumemade clothing patterns, (4) If sorted, products that take longer to make patterns are: (a) long dresses; (b) short dress; (c) deuce piece; and (d) modern kebaya.

\section{Conclusion}

The results of the research prove that the assessment patterns in the production/manufacture of women's clothing can be stated as follows:

The application of the grading system pattern order has resulted in: (1) a more precise pattern analysis; (2) fits better in size or wearability; and (3) the processing time is more efficient when compared to the construction/flat pattern.

Assessment and comparison of construction patterns and patterns in grading, successful and help to maximize, manage time, energy and, expenditure efficiency/economy.

Students' knowledge and skills regarding the technique of making patterns in three dimensions using 
dress form media, which are hereinafter referred to as patterns with assistants, are increasing.

There is an increase in production and skills in increasing and calculating time, which does not directly imply an increase in student achievement in making industrial and custom-made business.

Making industrial clothing and custom clothing can use the Grading Pattern technique/method.

\section{References}

Armstrong, H. J. (2010). Pattern Making for Fashion Design (5th ed.). Prentice Hall Publishing.

Cooklin, G. (2003). Pattern Grading for Women's Clotes: The Technology of Sizing. Blackwell Science Ltd.

Dai, B. H., \& Wang, X. Y. (2011). Research on intelligent clothing pattern auxiliary input and grading system. Advanced Materials Research, 175-176, 906-910. https://doi.org/10.4028/www.scientific.net/AMR.175176.906

Dove, T. (2016). Stretch to fit - made to fitł. International Journal of Fashion Design, Technology and Education, 9(2), 115-129. https:// doi.org/10.1080/17543266.2016.1167252

Herman, J., Mardiana, P. N., \& Irma, H. (2011). Kamus Mode Indonesia. Gramedia Pustaka Utama.

Hlaing, E. C., Krzywinski, S., \& Roedel, H. (2013). Garment prototyping based on scalable virtual female bodies. International Journal of Clothing Science and Technology, 25(3), 184-197. https://doi.org/10.1108/09556221311300200

Mulyawan, P. (2011). Analisa Pecah Mode Busana Wanita. BPK Gunung Mulia.

Price, J., \& Zamkoff, B. (1996). Grading Technique for Fashion Design (2nd ed.). Fairchild Publications.

Volpintesta, L. (2014). The Language of Fashion Design: 16 Principles Every Fashion Designer Should Know. Rockport Publisher.

Wening, S. (2013). Modul Pembuatan Busana dan Pengembangan Pembelajarannya. Konsorium Sertifikasi Guru. 